\title{
Africa's Urban Waste Management and Sanitation Challenges: Are Transfer Stations the Solution?
}

\author{
Manteaw, Bob Offei ${ }^{1} \&$ Johannes Boachie ${ }^{2}$ \\ ${ }^{1}$ Center for Climate Change and Sustainability Studies, University of Ghana, Accra, Ghana \\ ${ }^{2}$ KNUST African Institute of Sanitation and Waste Management, Accra, Ghana \\ Correspondence: Manteaw, Bob Offei, Center for Climate Change and Sustainability Studies, University of \\ Ghana, Accra, Ghana. Tel: 233-2-4426-9073. E-mail: rmanteaw@ug.edu.gh
}

\author{
Received: October 8, $2019 \quad$ Accepted: November 7, $2019 \quad$ Online Published: November 29, 2019 \\ doi:10.5539/ep.v9n1p1 \\ URL: https://doi.org/10.5539/ep.v9n1p1
}

\begin{abstract}
Africa's urbanization processes are seen as both a challenge and an opportunity for sustainable development. While these processes unfold differently in diverse countries across the continent, it has become increasingly apparent that surge urbanization, population growth and the lack of effective planning for an efficient waste management system have brought in its wake other challenges that have significant implications for public health and sustainable development. Thus, much as urbanization has the potential to drive Africa's growth and sustainable development agenda, current happenings in most of Africa's cities, in particular, also signal the negative impact of rapid and unplanned urbanization on sustainable development processes. Waste and sanitation management have become an enduring urban challenge across Africa. They come with significant cost to people and governments and as the search for lasting solutions continue, Waste Transfer Stations have emerged as an efficient management technology which has been embraced and deployed in some countries. While it has received praises in some quarters as an innovative technology, there is concern that such praises have muted critical issues of pollution, odor nuisance, cultural incompatibility and public health challenges, which, for the most part, are unrecognized or underestimated. The question then becomes: are Waste Transfer Stations the solution to Africa's urban waste and sanitation challenges?
\end{abstract}

Keywords: waste management, transfer stations, urbanization, pollution, innovation, sustainable development

\section{Introduction}

Waste Transfer stations have been deployed in many cities and urban communities around the world as an efficient mobility facility for solid waste management (Christensen, 2010; Zhao, Lu, \& Wang, 2015;). They are common features in waste management practices in most Western countries. In the last few years, however, the concept has been embraced by many African countries as it has very quickly found its way into countries such as Ghana and Nigeria where they have been adopted and deployed as an additional avenue to address the growing urban waste management and sanitation challenges (Oteng-Ababio et al., 2013; Simelane \& Romeela, 2015; Remigios, 2010). Ghana's experiment with waste transfer station is recent and ongoing; it is novelty and largely perceived by policy-makers as innovative and a timely intervention at a time when most urban communities in the country continue to struggle with waste and sanitation management challenges.

The Transfer station experiment in Africa has attracted mixed reactions from different quarters. While some praise it as innovative, others have criticized it for its pollution and public health implications (Marshall \& Farahbakhsh, 2013; Krupnick, 1991). For most people without any technical insights or understanding of such technologies and associated issues, the introduction of transfer stations seems to have already proved or signaled potential for success. These conclusions, for the most part, are based on public perceptions on the relative ease and convenience of waste haulage to final disposal sites (De Feo, De Gisi, \& Williams, 2013). While these seemingly positive reviews continue, it is also becoming apparent and indeed worrying that there are underlying public health issues that not many are talking about (Evans \& Kinney, 1984; Han, Zhou \& Li, 2014; Silva, 2013; Wang, 2019).

This, as is currently in the case of Ghana, make most of the reviews uncritical and uniformed especially when most people lack the ability or capacity to critically analyze other aspects of the transfer stations and to explain 
emerging issues in more critical terms. The location and operations of the two experimental stations in residential enclaves in Ghana's capital with high human and vehicular traffic have emerged as a major problem. There are emerging issues of noise, dust and odor pollution, air quality with significant public health implications (Capelli et al., 2011). Thus, beyond the current praises and positive reviews of the performance of waste transfer stations so far lie larger and deeper questions about their viability or effectiveness as dependable mechanisms to augment urban waste management approaches in urban Africa (Oteng-Ababio, Melara \& Gabbay, 2011).

This paper foregrounds Waste Transfer Station as an emergent technology for urban waste management in Africa. Even though transfer stations seem to have brought some innovation and efficiency in urban waste haulage especially in the cases of Ghana and Nigeria, the measure of their effectiveness has not been critically explored to establish its credibility and reliability. Current evaluation of the performance of waste transfer stations has been based on simplistic conclusions based on perceptions and impressions, which somehow ignores other critical considerations. Thus, even though the technology seems to have attracted a lot of attention in some cities in Africa, and in this case Accra and Lagos, capitals of Ghana and Nigeria respectively, its effectiveness, efficiency, and suitability have not been critically interrogated from the perspective of the unique cultural, social, environmental, spatial and engineering situations of many urban communities.

While the paper welcomes its introduction as well as support the current experiment in Accra, the paper is of the view that Africa's unprecedented urbanizing processes and its unique attributes and challenges have created a necessity for the uncritical introduction and acceptance of waste management technologies such as Waste Transfer stations as an 'innovative' intervention. While not disputing the innovative attribute of some of these technologies, the paper, however, doubts the potential of Waste Transfer stations to revolutionize solid waste management in Africa's rapidly urbanizing communities. It is our contention, therefore, that even though technologies such as Waste Transfer stations may be necessary and helpful in addressing Africa's urban sanitation challenges, existing institutional, social, environmental and cultural challenges impede the realization of its full potential. This is mainly because existing challenges such as rapid population growth, urbanization, the lack of effective urban planning, gridlocked vehicular traffic situation and, more importantly, the absence of an integrated waste management system, makes it somehow problematic for urban communities in Africa with any of these attributes to leverage the full potentials of transfer stations as a waste management technology.

In foregrounding the emergence of transfer stations in Africa, this paper attempts a social science interrogation of the perceived game-changing roles of transfer stations in urban waste management in Africa. Without being too technical, the paper argues that irrespective of the perceived efficiency of transfer stations, certain unique aspects of waste management practices in most urban communities in Africa and particularly Accra, Ghana, problematize the efficiency and effectiveness of transfer stations as the technology to revolutionize the urban waste management landscape in Africa (Mariwah, 2012). As the clamor begins for more transfer stations in Accra, obviously based on uniformed individual impressions, the paper sees opportunity to highlight the need for a more critical examination of the concept of waste transfer stations and to establish its suitability in Africa's unique urban contexts. Ours, therefore, is to highlight underlying issues that have been ignored in the evaluation of current performance of transfer stations in Ghana and to call for a rethink of how the technology could be best utilized. 


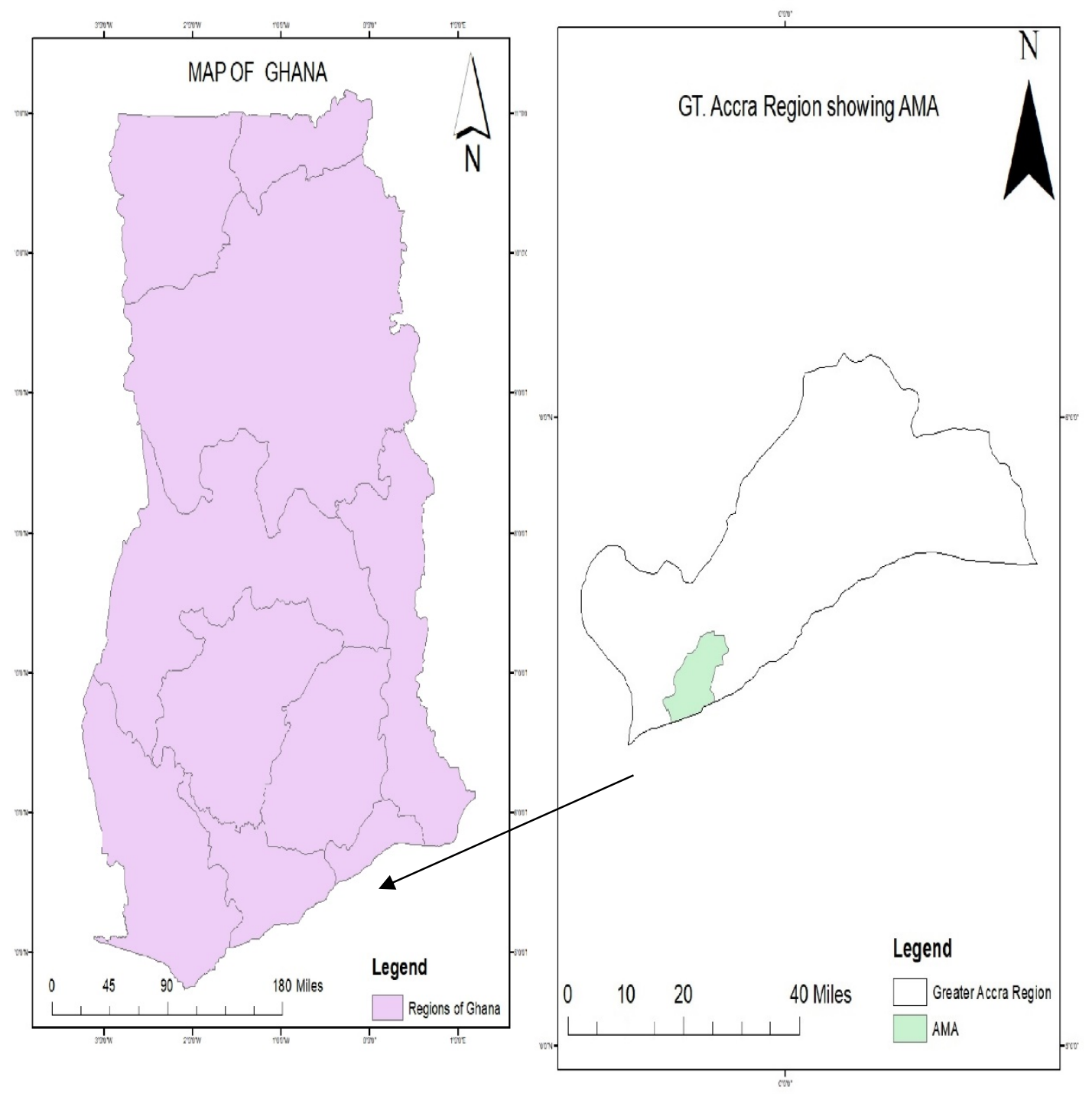

Figure 1. Map showing study area

Using the city of Accra, the capital of Ghana and located within the Accra Metropolitan Assembly (AMA) as referenced above, the paper first locates Africa's waste and sanitation challenges in the broader context of urban development and as a way of clarifying how urban population growth and a lack of forward-looking planning culture have contributed to the current situation in many urbanized communities across Africa. This will be followed by a discussion on the suitability of transfer stations as a technology to address Africa's urban waste management challenges. Here, the different opportunities and challenges will be critically assessed and highlighted to facilitate a dispassionate assessment of what works and how such technologies should be deployed. The paper will conclude with a discussion on ways forward and will look at best possible ways to integrate as well as adapt such technologies to suit the unique particularities of Africa's urban waste management context. The principal organizing question for this paper is: Do waste transfer station provide the required solutions for Africa's waste and sanitation challenges?

\section{Urban Development and Africa's Waste Crisis}

Africa is rising, so goes the current narrative on Africa's growth and development prospects (Hove, Ngwerume, \& Muchemwa, 2013). While most of these narratives are in direct reference to economic indicators and existing 
potentials for Africa's development, there is no doubt that the rapidly urbanizing landscapes of Africa, characterized by sprawling cities, high-rise buildings, and flashy city lights epitomize an urban revolution in most of Africa's cities. Beneath the glow of the flashy city lights, lie a dark and gloomy contrast: inner city slums, inadequate planning, traffic gridlock, poor waste management, sanitation, hygiene and public health challenges which all converge to define certain underlying characteristics of Africa's urban development process an aspect of which this paper seeks to highlight (Bartram \& Cairncross, 2010; Peter \& Yang, 2019)

As the continent's surge urbanization processes continue, it is also becoming increasingly worrying that most cities and urban communities in Africa, particularly in Sub-Saharan Africa, are overwhelmed by the pace and intensity of urbanization and are not adequately prepared to deal with the consequences of the change process (El Araby, 2002; Hove et al., 2013). Of particular concern is the issue of waste, sanitation and public health management, which has become pervasively recalcitrant in most of existing and emerging urban communities in Africa. Most cities and towns across Africa lack the requisite resources and infrastructure to address the challenges of waste management, which is also a consequence of the increased populations that many believe is driving Africa's unprecedented urbanizing trend (McKinsey, 2016). With cities living up to their reputation of serving as engines of growth and hubs for economic development (Duranton, 2009), they have been at the heart of the Africa rising agenda and continue to provide the requisite pull factors that attract migrants from rural areas into urban communities.

The result is the emergent phenomenon of surge urbanization - the radical and rapid shift in population flows from rural to urban communities resulting in the creation of unplanned human settlements in urban societies (Fei-baffoe, Nyankson, \& Gorkeh-miah, 2014, Ahsan et al., 2014). The offshoot of this situation is the concentration of growing populations in moderately large cities and the rampant creation of unplanned human settlements with attendant challenges of waste management and sanitation challenges. As the urbanization trends in Africa continue forcefully, so has the burden of waste and sanitation management in these communities increased (Silva, 2013). Sanitation management and hygiene have become critical aspects of urban management in Africa and, for the most part, a debilitating public health challenge with significant implications for Africa's quest for sustainable development (Parrot, Sotamenou, \& Dia, 2009).

Historically, urban planning (then known as town planning in colonial Africa) has been employed as a tool to manage public health and to demonstrate the consanguine relationship that has existed overtime between public health and town planning (Njoh, 2007). Town planning and public health are rooted in a common ancestry, which dates back to the sanitary movement of the $19^{\text {th }}$ century. At the time, and as Njoh, 2012 puts it: "public health elements featured prominently in town planning legislation. In fact, town planning practice was pre-occupied with implementing health policy" (p. 10). There were commonplace town planning ordinances designed deliberately to manage public health and within the built environment. Urban layouts, and the morphological relationships between streets blocks and settlement units were deliberate and all aimed at preventing urban outbreaks of infectious diseases. Sanitation and public health concerns were integral in urban planning processes and associated issues were addressed comprehensively at the initial stages of planning processes as a preventive measure (Rydin et al., 2012). The mindset then was to prevent the occurrence of disease outbreaks rather than to cure them once it has happened.

With surging urban populations and the creation of instant human settlements in contemporary urban development in most of Africa, urban planners and local authorities are overwhelmed by the pace of population growth and the rates at which unplanned human settlements spring up in these communities. There has since been a total disconnect between public health and urban planning. Corburn (2004) highlights this fact by noting that "although public health and urban planning emerged with the common goal of preventing urban outbreaks of infectious diseases, there is little overlaps between the fields today" (p.541). The current rate of population growth and the rates at which unplanned human settlements spring up in urban communities seem to have overwhelmed most urban planners and local authorities. In the process, waste, sanitation, hygiene and public health considerations have lost their priority place in contemporary urban planning. Most urban settlements therefore spring up without any conscious consideration for how waste will be managed. Waste Management efforts and approaches in many urban and urbanizing communities in Africa are not planned in an integrated manner; they are largely afterthoughts and are developed and implemented when settlements have already sprung up.

Such attitudes and approaches towards waste management in Africa's current urbanizing processes have become common place and very instrumental in the creation of the continent's current waste and sanitation crisis. The problem is widespread and almost stylized as many if not most Sub-Saharan urban communities will unashamedly list waste and sanitation management as a priority social and environmental challenge that needs 
critical attention. Njoh (2012) gives a profound and vivid description of the expanse and reach of what we describe in this paper as Africa's waste and sanitation dilemma. He describes it as widespread and "manifold manifestations of unhygienic and insalubrious conditions that characterize human settlements in Africa from Cairo to Cape Town, and from Dakar to Mogadishu" (Njoh, 2012). It is indeed a human settlement problem, which, as we have indicated, emerged out of stylized urban population growth across Africa. The problem, as we have indicated, is typical in most urban communities in Africa. Tammemag (1999) reiterates the link between Africa's waste problems with surge urbanization by observing that "The waste disposal problem is closely related to population growth and urbanization" (p.5).

From the United Nations Millennium Development Goals (MDGs) and currently the Sustainable Development Goals (SDGs), the imperative to assure and ensure hygiene and public health in sustainable development processes within and among countries, especially in Africa, has emerged as a priority development concern and has rightly so challenged governments at national and subnational levels to explore the requisite solutions. This is also against the background of increases in population growth and the rapidly urbanizing processes that currently characterize most urban communities in Africa. There is a lingering fear that if conscious and more aggressive efforts are not made to address current waste, sanitation, hygiene and public health challenges, the ensuing consequence may prove significantly devastating to Africa's sustainable development aspirations (Watson et al., 2019). The search for innovative approaches to manage Africa's urban waste has seen the emergence of Waste Transfer Stations in some countries as appropriate technologies with the requisite capability to help address Africa's urban waste crisis.
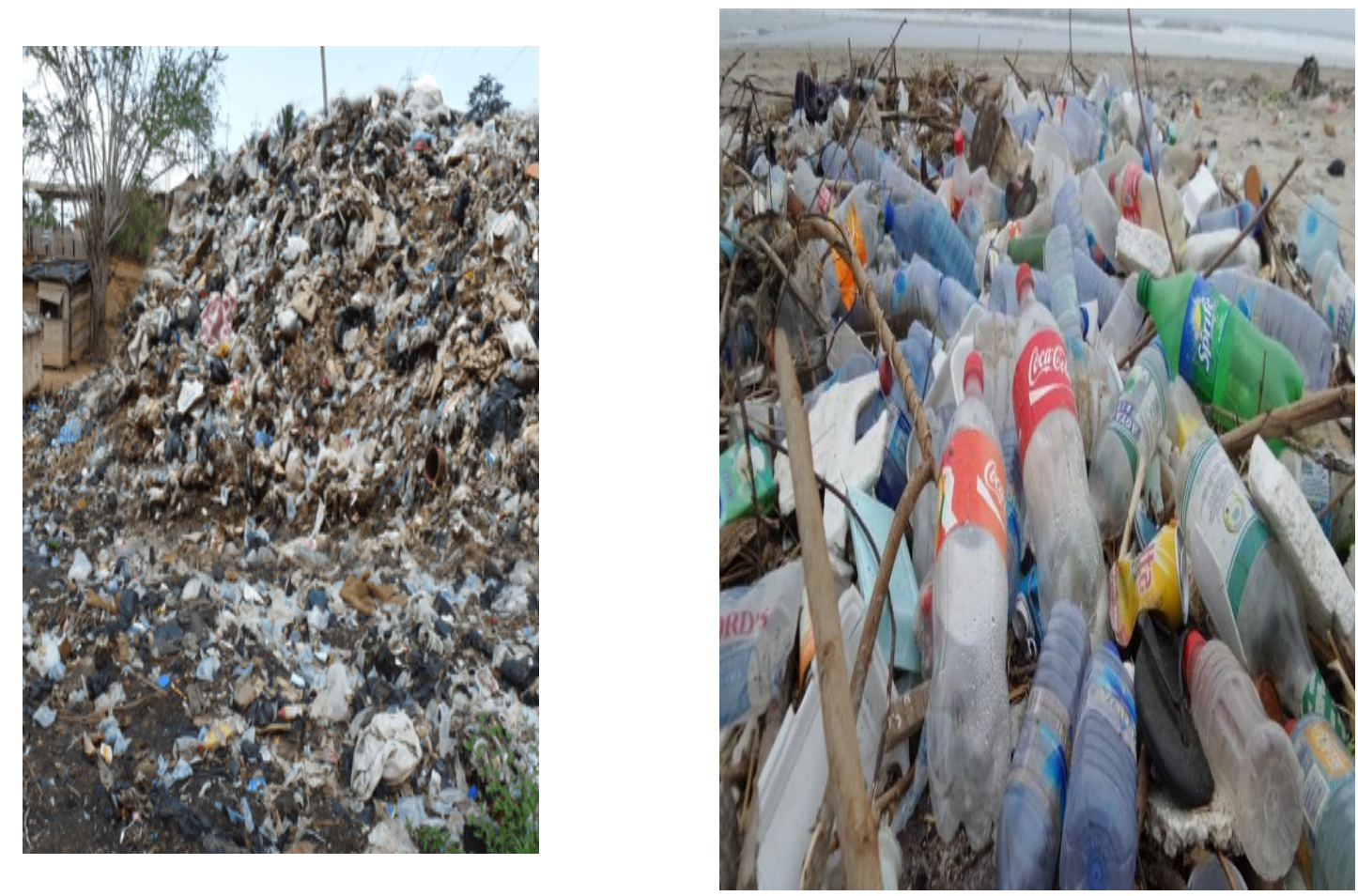

Figure 2. Africa's waste crisis

\section{Transfer Stations: Analyzing a Concept}

The threat of the potential impacts of Africa's waste crisis on sustainable development processes has been well acknowledged (Parrot et al., 2009; Of et al., 2018) across Africa and in individual countries. This has prompted the search for appropriate and effective waste management technologies and approaches. Among these approaches is the exploration and adoption of best practices in waste management from different jurisdictions and cultures. The complexities of Africa's urban development processes and its consequence on waste generation and management have compelled the adoption of waste transfer stations as an urban waste management technology in some of Africa's cities. Culturally, transfer stations are alien technologies in Africa's waste 
management approaches. They are recent introductions and have been transferred as technologies of best practice from Western and advanced countries where they are widely deployed in both rural and urban waste management systems (Ramaswami, Baidwan \& Nagpure, 2016). As waste management technologies, transfer stations play an important role in a community's total waste management system by providing a convenient linkage between a community's solid waste collection process and final disposal or processing facility.

In its simplest form, a solid waste transfer station is a waste receiving facility at a carefully selected location in a community from where refuse is transferred from collection trucks, and possibly other vehicles, to larger capacity vehicles for shipment to a final disposal site or a waste processing facility (Godri et al., 2010). While sizes may differ significantly among transfer stations from community to community, they serve the same basic purpose of being a transit point for the consolidation of waste from multiple collection vehicles and transferred into larger, high-volume transfer vehicles for more economical shipment to distant disposal sites (Ahuja \& Bahukhandi, 2009). Technically, Waste Transfer Stations are transportation technologies designed to infuse efficiency in waste handling and mobility (Abduli, Naghib, Yonesi \& Akbari, 2011). Invariably, transfer stations are purpose-built facilities designed to serve as transit collection points solid waste collection and haulage in a chosen location.

As a common feature, a Waste Transfer Station will typically have a designated receiving area where waste collection vehicles discharge their loads. The waste is often compacted, then loaded into larger vehicles which are usually larger and bigger transfer trailers. Depending on haulage distances and the different purposes for the transported waste, stations could also use intermodal containers, railcars, and barges as a means of transportation. Thus, long-haul shipment to a final disposal site - typically a landfill, waste- to-energy plant, or a processing facility may require the use of other means of transportation other than trucks to allow for larger volumes of haulage. They are not supposed to be used for long-term storage of waste (Christensen, 2010); they serve mostly as designated receiving points where collected wastes are consolidated and very transferred into larger vehicles with a view to moving them quickly offsite.

The core function of a transfer station, therefore, is to serve as a temporary waste receptacle to increase the turnaround times of domestic waste collection trucks (Akafia, 2014). The choice of location for such facilities is usually strategic and is given a lot of careful consideration during the design process. A well-selected location ensures convenience and easy mobility (Christensen, 2010). Trucks are expected to reduce travel times to and from disposal sites and to leverage the general economic advantages derived out of reduced travel time and haulage costs.

\section{Africa's Waste Crisis and the Sanitation Imperative}

A drive around select streets and communities in Accra on any day will almost immediately bring into sharp focus the extent of the waste crisis in the city. Uncollected heaps of garbage, garbage-filled drains and litter provide unsightly scenes that poignantly depict the city's sanitation and hygiene challenges (Parrot et al., 2009). The situation gets worse when it rains and when a mix of solid and liquid waste clash sometime very violently with running water to create floods in communities. Such situations are recurring and almost predictable annually with disastrous consequences. Climate change and associated changes in rainfall trends and intensity have complicated the situation by leaving in its wake insalubrious conditions that bring different disease outbreaks with significant repercussions for public health (Zhao et al., 2015). This is not just an Accra or Ghana story; it is a Sub-Saharan African urban reality that is playing out differently in different countries, different cities and different communities. It is a reality reflected in the recent Mercer Quality of Living Survey City Sanitation rankings 2018 where most African cities occupy the bottom positions in the City Sanitation Rankings. The table below shows the positions of some of Africa's major cities in the City Sanitation Rankings. 


\begin{tabular}{lll}
\hline Ranking & City & Country \\
\hline 203 & ACCRA & GHANA \\
204 & OUAGADOGOU & BURKINA FASO \\
205 & KHARTOUM & SUDAN \\
209 & BANGUI & CENTRAL AFRICAN REPUBLIC \\
211 & ABIDJAN & COTE D'IVOIRE \\
213 & LUANDA & ANGOLA \\
215 & ABUJA & NIGERIA \\
215 & BAMAKO & MALI \\
217 & N'DJAMENA & CHAD \\
218 & DAR ES SALAAM & TANZANIA \\
219 & CONAKRY & GUINEA REPUBLIC \\
220 & LAGOS & NIGERIA \\
221 & ADDIS ABABA & ETHIOPIA \\
222 & HARARE & ZIMBABWE \\
25 & BRAZZAVILLE & CONGO \\
\hline
\end{tabular}

Figure 3. Major cities in the city sanitation rankings

As discussed earlier, there is a direct link between waste management and Africa's sanitation challenges (Owusu, 2010). The persistence of the waste management challenge in urban communities such as Accra and Lagos is reason why technologies such as waste transfer stations have been adopted. While experimentation with known technologies such as waste transfer stations and other innovative mechanisms are in the right direction, adoption of these technologies are sometime not carefully considered and based solely on the urgency and desperation for solutions which sometimes results in the wrong adoption and application of solutions.

The waste problem in Accra come in tow folds: collection challenges and disposal or final processing. The lack of waste infrastructure such as landfills and waste processing facilities contribute to the amount of waste that remain uncollected. Collection trucks are insufficient and have to travel long distances through gridlocked urban traffic to the few available final disposal sites. This has affected the collection turnaround times leading to large quantities of waste remaining in communities, households and streets uncollected. The longer waste remain uncollected, the more complex the sanitation challenge becomes (Tumwebaze, Orach, Niwagaba, Luthi \& Mosler, 2013). Uncollected waste create unsightly and insalubrious conditions in communities; some end up in drains and contribute to community flooding which more often than not lead to disasters and other catastrophic consequences such as loss of life and property (Blaikie, Cannon, Davis \& Wisner, 2005).

Available statistics indicate that the city of Accra on the average generates 3800 metric tons out of which 2200 metric tons is collected. About 1000 metris tons go to landfills and dumpsites while the rest either stay in communities or end up in unconventional places (Miezah et al., 2017). This has remained a major nexus between the city of Accra's waste and sanitation crisis. It is a problem that is compounded by the fact that waste generated in most of Ghana, and in Accra for that matter, are not segregated at source; all waste streams are mixed and are expected to be collected and dumped together. There is currently no culture of waste source separation or segregation in Ghana (Abalo et al, 2018). Most household and industrial waste are mixed and create significant problems in any effort to manage waste in an integrated way. This has remained a major challenge in the management of waste in Accra and other urban communities. With the exception of about 600 tons of waste generated in Accra that goes to the only designated waste recycling center in Accra, the rest of the waste generated are dumped in landfills or other unauthorized locations to add to the sanitation dilemmas of urban communities (Owusu, 2010).

With increasing population growth resulting in urban sprawl, land availability and access have become a critical issue in urban waste management in most of Africa (Abalo et al, 2018). The pressures on available land for human settlement has made it extremely difficult for any urban land especially in and around the city of Accra to be set aside for waste disposal or even processing. Land in Ghana are usually owned by families and individuals and with such high demands for land for human settlement, most land owners are unwilling to make land 
available for waste management and even more so when there is so much money to be made through housing for human settlement. This is particularly so in urban communities where issues of waste disposal and waste processing have become a clear case of Not-In-My-Backyard (NIMBY) and has forced both government and private waste management operators to look further afar and in distant locations for suitable lands to use as final disposal sites.

The consequence is that travel distances to such sites by collection trucks is not only tedious and time consuming, but also extremely expensive. The long haulage distances are further complicated by traffic delays due to the existing culture of city traffic gridlock and paralysis, a situation, which characterizes most cities and town across Africa (Kibunja, 2009). This situation has very much affected waste collection frequencies and efficiencies in cities; it ultimately explains the unsightly spectacles of litter and heaps of uncollected garbage on streets and in communities. It is also the situation, which has motivated the introduction of Waste Transfer stations in cities like Accra and Lagos to serve as an avenue to get around this collection and transportation problem.

\section{Waste Transfer Stations in Urban Africa}

Transfer stations are to provide a faster haulage system by serving as transit points for onward transportation of waste to final disposal sites. And, as expected, the two experimental stations in Accra have shown potential to assure efficiency in waste collection and haulage. The problem, however, is that much as collection times have improved as a result of the locations of the transfer stations, there have also been certain emergent issues that seem to be counterproductive to perceived benefits of the transfer stations. The issues are incipient and are not given the needed attention even though routine Environmental Impact Assessments (EIA) had right $t$ at the onset highlighted some of these issues. In their current forms, the emerging issues could blight the potential advantages of transfer stations as there is real potential for some of these initial challenges to escalate into full-scale urban planning and public health challenges. As has been experienced in other jurisdictions around the world (Agus, Zhang \& Sedlak,2012; Zhao et al., 2015).

As the problems fester and as discussions continue on the possibilities of increasing the number of transfer stations in the city of Accra and, also extend to other cities in the country, it is important that the current operations of transfer stations are subjected to critical scrutiny to establish their suitability in helping to address Africa's waste and sanitation challenges. Such scrutiny, we believe, will facilitate a conscious assessment of the use of Transfer Stations in cities such as Accra and Lagos and to establish their merits and demerits. Accra's current experiment with Transfer Stations has received some good reviews even though not a lot of critical attention has been given to its negative externalities. The praises so far, are coming from waste management operators who are hailing the technology as a success because of the increase in collection turnaround times, volumes collected and of course the money saved in shorter haulage times. The early impressions of success of the two experimental stations in Ghana have already prompted talks for the introduction of more of such technologies around the city of Accra and as part the Clean Ghana Campaign a government-led initiative to rid the city of Accra of filth.

Lagos, in Nigeria, is also on a similar mission. Having already established some transfer stations across the city, there are plans to increase the number of transfer stations in and around Lagos as well as refurbish and modernize existing ones around the city to create what is described as waste collection 'hubs' around the city to bring efficiency in solid waste management (https://www.nipc.gov.ng/visionscape-modernises-lagos-state-transfer-loading-stations/). Unlike, the city of Lagos, Accra's experience with Transfer Stations is relatively recent and may not be as elaborate and expansive as what has gone on in Lagos for a while now. Notwithstanding, Accra's nascent experience has proved that transfer stations could be both efficient as a technology and profitable. Many waste collection companies see the introduction of waste transfer station as positive; they seem to believe that the new system has enhanced both their efficiency and profitability. They see it as being much more profitable for a waste collector to tip waste at transfer station to reduce its commuting time to final disposal sites. In a city characterized by traffic gridlock and sometime paralysis, complicated by the distant locations of final disposal sites, the introduction of transfer stations has not only reduced travel times for waste collectors, but has also revolutionized the operations and bottom lines of waste management service providers. That certainly provides the logic for further increases in the number of transfer stations in the city of Accra and it is in this logic that the critical question lays: are transfer stations the right solutions for Africa's urban waste crisis?

\section{Transfer Stations: The Right Solutions for Africa?}

From both the experiences of Ghana and Nigeria, as well as a few other African countries that have experimented with Waste Transfer Stations, it is evident that their contribution to the management of waste 
especially in busy and congested urban areas have been significant. This, as in the case of Lagos and Accra, has justified the call for further investments in transfer stations to boost waste and sanitation management services in urban communities. As ratings for the performance of transfer stations remain largely positive, it is also obvious and indeed worrying that most of such evaluations are based on perceptions of convenience in mobility, increase in volumes of waste hauled and reductions in haulage travel times and relatively to status quo operations.

The paper, as stated earlier, supports the introduction of such innovations and would support further investments. However, we are of the view that much as current performances are largely positive there are underlying issues that are muted not so much because of perceived advantages, but because not many of those who are praising the performance of transfer stations have the technical insights and capacity to see what else is being sacrificed in the process. It is tempting, therefore, for the question to be asked as to whether transfer stations indeed provide the needed solutions to Africa's urban waste and sanitation challenges. Answers maybe mixed and varied; however, it is important that transfer station operations in urban communities are critically scrutinized to establish both their strengths and weakness and to pave the way for improvements in service delivery.

To begin with, the primary function of a Waste Transfer Station as observed by (Christensen, 2010) is to facilitate easy and convenient collection, sorting and transportation of waste materials either to processing facilities or final disposal sites. Location therefore is critical if the expected efficiencies and economic benefits are to be derived. This, however, is based on the assumption that all waste coming to the station are segregated at source and characterized (Ayeleru, Ntuli \& Mbohwa, 2016). Real efficiency of a waste transfer station is therefore measured on the extent and quality of waste segregation which ultimately constitutes a critical function and attribute of a waste transfer station. Such attributes in some instances also undergird the design of Transfer Stations.

Ghana, like most Sub-Saharan African countries, lack a culture of waste segregation at source (Owusu-sekyere \& Harris, 2013; Abalo et al, 2017). Waste streams are not segregated; they are mixed and collected as mixed (Miezah et al., 2017). This creates a fundamental problem in waste management, which also makes it counterproductive to the full functionality of waste transfer stations. Against the background of current positive opinions about transfer stations in both Accra and Ghana, and also the fact that waste segregation is not practiced in this communities, it becomes obvious that Transfer Stations as adopted by Ghana and Nigeria have been repurposed to suit the contextual realities of the cities Accra and Lagos (Oteng-Ababio, 2015). Thus, and with rapidly increasing urban populations, unplanned settlements, constantly gridlocked road traffic situations and long travel distances to landfills sites, repurposing of waste transfer stations provides a semblance of efficiency in the collection and haulage to final disposal sites.

Segregation and distribution of characterized waste materials for waste processing facilities are out of the picture, for the most part in Ghana, in particular, and this is because the general lack of a waste segregation and recycling culture has also created a situation where there are not many waste processing facilities. Recycling and waste processing have for a while now been alien practices in Ghana even though there is a growing awareness of the importance of recycling and material recovery from waste. Undoubtedly, the lack of a waste segregation culture does not only reduce the efficiency of waste transfer stations, but also serves as a significant dent in what could be described as an Integrated Waste Management System. This therefore renders Accra's current experiment with Waste Transfer Stations only as an interim waste collection center for easy mobility and economically efficient haulage to terminal disposal sites.

Besides the reduction of the purpose of Waste Transfer Stations to collection and haulage sites, there is also an aspect of the operations that is yet to attract public attention even though complaints abound. The public health implications of Waste Transfer Stations in Accra's two experiments are just coming to the fore and are yet to attract conscious attention to establish current and future health impacts on surrounding communities (Z. Duan, W. Lu, D. Li, H. Wang, 2014; G.Y. Li, Z.Y. Zhang, H.W. Sun, J.Y. Chen, T.C. An, B. Li 2014,). Challenges such as odor pollution; odor nuisance; particulate matter etc. are usually issues associated with urban waste management and transfer stations in many jurisdictions and are issues that are, addressed through Environmental Impact Assessments (EIA). Scientific evidence abounds in how populations living close to Waste Transfer Stations have suffered from lung-related diseases (Godri et al., 2010; Krupnick, A.J., 1991). Even though no focused post-implementation study has been done in Accra to ascertain the current health and environmental impact of transfer stations on people and communities around the two stations, initial Environmental Impact Assessment (EIA) conducted under the laws of Ghana hinted of potential health impacts that should be addressed (Adjarko, Gemadzie \& Agyekum, 2016). By existing Legislative instruments in Ghana (Cobbinah, Black \& Thwaites, 2015), the facilities would not have come into existence without a clearly stated and documented mitigation plan for any environmental or health hazards picked up by the EIA. The fact current 
environmental and health challenges exist as part of the operations of the Stations and the fact that nothing is being done in spite of EIA results also raises questions about the suitability of Transfer Stations to Africa's urban context

Odor and air pollution, in particular, have been major issues in the vicinity of the two experimental transfer stations in Accra. This is primarily because the two stations receive increased volumes of waste and at very frequent intervals and store them much longer than required before onward transportation to disposal sites. Emissions from trucks converge with odor and particulate matter circulations from the waste materials to pollute the air within and beyond the locations of the stations (De Feo, De Gisi \& Williams, 2013). Odorants coming from either waste in transit trucks or at the stations from stored waste materials awaiting transportation are considered volatile trace compounds with significant public health implications (Clavreul, Baumeister, Christensen, Damgaard 2014 ; Agus, Zhang, Sedlak, 2014; Zhao et al., 2015). Such compounds typically include Sulphur compounds, oxygenated compounds (alcohols aldehydes, ketones, acids and esters), aromatics, terpenes, halo-genated compounds and saturated and unsaturated hydrocarbons. Some of these trace compounds, including chlorofluorocarbons (CFCs), have very detrimental effects on humans and the environment.

It is on this basis that we remain cautiously excited by the introduction of Waste Transfer Stations in Accra and by extension Africa's urban contexts. While we acknowledge the reality that Waste Transfer Stations have brought some improvement in waste and sanitation management in Ghana, there are other aspects of its operations that are yet to be highlighted and addressed. Perhaps, the two experimental stations should provide the much needed lessons to justify the question of whether Waste Transfer Stations provide the requisite solutions to Africa's urban waste management challenges. Current operations and emerging issues provide ample reason for focused studies both qualitative and quantitative to establish not just the efficiency of such facilities but also their cultural feasibility and relevance considering the structural make up of Africa's urbanized communities as well as waste management practices.

\section{Conclusion}

Decisions on whether a transfer station is appropriate for an individual community is based on determining if the benefits outweigh the costs (Lober, 1993). Decision-makers therefore consider a number of factors which invariably include the planning, siting, designing, and operating costs against the savings the transfer station might generate from reduced hauling costs. Ghana's choice of transfer stations as a waste management technology may have considered all these, but as it has become evident from current operations, solutions to the current waste and sanitation challenges may not necessarily rest in the importation and application of perceived best practice solutions from foreign cultures without adjustments to suit local cultures.

Certainly, the idea of Waste Transfer Stations sounds innovative and has the potential to contribute significantly to the quest for solutions. However, what has also become apparent in the process both in Ghana Nigeria is that not a lot of thought was given to the adoption of such technologies and particularly from a socio-cultural perspective. Fact remains that most of Africa's growing cities, and in this case Accra and Lagos, have unique cultural and social attributes which in many ways impede the full utilization of the efficiency of transfer stations as waste haulage technologies.

The lack of planning, rapid urbanization and constant vehicular traffic gridlock on urban roads work against the expected efficiency of transfer stations. Transfer stations, technically, are transit points mostly in the center of urbanized communities for the efficient mobility and disposal of waste (Kulcar,1996). Waste materials brought to these points are not for longer time storage, but are to be sorted and hauled very speedily to either processing facilities or final disposal sites. The lack of free mobility and sometimes the lack of adequate logistics and infrastructure for quick mobility have created a tendency where waste materials are kept at these stations much longer than desired and as a result defeat the essential purpose of the station.

In most of such instances, and at least in Ghana's two experimental stations, delays in moving waste materials have created additional socio-environmental challenges which were not adequately considered in the introduction of the technology. Odor nuisance, air pollution, noise pollution and litter from collection trucks are creating serious public health challenges which are yet to be given any real attention in the management of the negative environmental impacts associated with this venture. The paper is therefore concerned that much as the technology continues to be seen as innovative, there are aspects of it that are problematic and require urgent attention. And, it is against this background that this paper concludes that Waste Transfer Stations, as emergent technologies with innovative capabilities, may not necessarily be the answer to Africa's urban waste and sanitation challenges. 


\section{References}

Abalo, E. M., Peprah, P., Nyonyo, J., Ampomah-Sarpong, R., \& Agyemang-Duah, W. (2018). A review of the triple gains of waste and the way forward for Ghana. Journal of Renewable Energy.

Abduli, M. A., Naghib, A., Yonesi, M., \& Akbari, A. (2011). Life cycle assessment (LCA) of solid waste management strategies in Tehran: landfill and composting plus landfill. Environmental monitoring and assessment, $178(1-4), 487-498$.

Adjarko, H., Gemadzie, J., \& Agyekum, K. (2016). Construction elated environmental laws and policies in Ghana: a literature review. Asian Journal of Science and Technology, 7, 2984-2992.

Agus, E., Zhang, L., \& Sedlak, D. L. (2012). A framework for identifying characteristic odor compounds in municipal waste water effluent. Water research, 46(18), 5970-5980.

Ahuja, N. J., \& Bahukhandi, K. D. (2009). Expert systems for Solid Waste Management: A Review.

Akafia, D. A. (2014). Solid waste collection and willingness to pay for better service in Tema, Ghana (Doctoral dissertation).

Ahsan, A., Alamgir, M., El-Sergany, M. M., Shams, S., Rowshon, M. K., \& Daud, N. N. N. (2014). Assessment of municipal solid waste management system in a developing country. Chinese Journal of Engineering, 111. https://doi.org/10.1155/2014/561935

Ali, A. (2010). Wasting time on solid waste in developing countries. Waste management, 30(8-9), 1437.

Ayeleru, O. O., Ntuli, F., \& Mbohwa, C. (2016). Municipal solid waste composition determination in the city of Johannesburg.

Bartram, J., \& Cairncross, S. (2010). Hygiene, sanitation, and water: forgotten foundations of health. PLoS Medicine, 7(11). http://dx.doi.org/10.1371/journal.pmed.1000367.e1000367

Blaikie, P., Cannon, T., Davis, I., \& Wisner, B. (2005). At risk: natural hazards, people's vulnerability and disasters. Routledge.

Black, M., \& Fawcett, B. (2008). The last taboo: opening the door on the global sanitation crisis. London: Earthscan Publications Ltd.

Capelli, L., Sironi, S., Del Rosso, R., Céntola, P., Rossi, A., \& Austeri, C. (2011). Odour impact assessment in urban areas: case study of the city of Terni. Procedia Environmental Sciences, 4, 151-157.

Christensen, T. H. (2010). Waste Transfer Stations. Solid waste technology \& management, 1, 311-318. https://doi.org/10.1002/9780470666883.ch23

Clavreul, J., Baumeister, H., Christensen, T. H., \& Damgaard, A. (2014). An environmental assessment system for environmental technologies. Environ. Model. Software, 60, 18-30.

Control, D. (2007). Title : Solid waste collection and transportation. 36-54.

De Feo, G., De Gisi, S., \& Williams, I. D. (2013). Public perception of odour and environmental pollution attributed to MSW treatment and disposal Facilities: A Case study. Waste Management, 33(4), 974-987.

Duan, Z., Lu, W., Li, D., \& Wang, H. (2014). Temporal variation of trace compound emission on the working surface of a landfill in Beijing, China. Atmospheric Environment, 88, 230-238.

Duranton, G. (2009). CHAPTER 3 Are Cities Engines of Growth and Prosperity for Developing Countries?. Urbanization and growth.

El Araby, M. (2002). Urban growth and environmental degradation: The case of Cairo, Egypt. Cities, 19(6), 389400 .

Evans, J. S., Tosteson, T., \& Kinney, P. L. (1984). Cross-sectional mortality studies and air pollution risk assessment. Environment International, 10, 55e83. https://doi.org/10.1016/0160-4120(84)902332

Fei-baffoe, B., Nyankson, E. A., \& Gorkeh-miah, J. (2014). Municipal Solid Waste Management in Sekondi-Takoradi Metropolis, Ghana. Journal of Waste Management. https://doi.org/10.1155/2014/823752

Gertsakis, J., \& Lewis, H. (2003). Sustainability and the waste management hierarchy: A discussion paper on the waste management hierarchy and its relationship to sustainability. Melbourne: EcoRecyle Victoria. Retrieved from http://www.ecorecycle.vic.gov.au/resources/documents/TZW_Sustainability_and_the_Waste_Hierarchy_ $\% 282003 \% 29$.pdf [Accessed 23 April 2013 
Godri, K. J., Duggan, S. T., Fuller, G. W., Baker, T., Green, D., Kelly, F. J., \& Mudway, I. S. (2010). Particulate matter oxidative potential from waste transfer station activity. Environmental health perspectives, $118(4)$, 493-498. https://doi.org/10.1289/ehp.0901303

Han, L., Zhou, W., Li, W., \& Li, L. (2014). Impact of urbanization level on urban air quality: A case of fine particles (PM2.5) in Chinese cities. Environmental Pollution, 194, $163 \mathrm{e} 170$. https://doi.org/10.1016/j.envpol.2014.07.022

Hove, M., Ngwerume, E. T., \& Muchemwa, C. (2013). The urban crisis in Sub-Saharan Africa: A threat to human security and sustainable development stability. International Journal of Security and Development, 2(1), 7. https://doi.org/10.5334/sta.ap

Kibunja, N. J. (2009). Traffic Congestion Problems in Nairobi: An Examination of Uhuru Highway.

Kulcar, T. (1996). Optimizing solid waste collection in Brussels. European Journal of Operational Research, 90(1), 71-77.

Krupnick, A. J. (1991). Transportation and Urban Air Pollution in Developed and Developing Countries. Transportation Research Record 1312. Transportation Research Record, National Research Council, Washington, D.C.

Li, G., Zhang, Z., Sun, H., Chen, J., An, T., \& Li, B. (2013). Pollution profiles, health risk of VOCs and Biohazards emitted from municipal solid waste transfer station and elimination by an integrated biological-photocatalytic flow system: A Pilot-Scale Investigation. Journal of hazardous materials, 250, 147-154.

Lober, D. J. (1993). Beyond self - interest: a model of public attitudes towards waste facility siting. Journal of Environmental Planning and Management, 36(3), 345-363.

Marshall, R. E., \& Farahbakhsh, K. (2013). Systems approaches to integrated solid waste management in developing countries. Waste Management, 33(4), 988-1003.

Mariwah, S. (2012). Institutional arrangements for managing solid waste in The Shama-Ahanta-East Metropolis, Ghana. Journal of Sustainable Development in Africa, 14(6), 292-312.

Miezah, K., Obiri-Danso, K., Kádár, Z., Heiske, S., Fei-Baffoe, B., Mensah, M., \& Meyer, A. S. (2017). Municipal solid waste management in a low income economy through biogas and bioethanol production. Waste and biomass valorization, 8(1), 115-127.

Muniafu, M., \& Otiato, E. (2010). Solid waste management in Nairobi, Kenya. A case for emerging economies. The Journal of Language, Technology \& Entrepreneurship in Africa, 2, 342-50.

Njoh, A. (2007). Planning power: Town Planning and social control in colonial Africa. uCl Press.

Njoh, A, J. (2012). Urban Planning and Public Health in Africa.

Owusu-sekyere, E., \& Harris, E. (2013). Forecasting and planning for solid waste generation in the Kumasi Metropolitan Area of Ghana: An ARIMA Time Series Approach. International Journal of Social Sciences, 2(4), 69-83.

Oteng - Ababio, M. (2015). In future directions of municipal solid waste management in Africa, pp-155-17.

Oteng-Ababio, M., Melara, J. E., \& Gabbay, O. (2013). Solid waste management in African cities: Sorting the facts from the fads in Accra, Ghana. Habitat International, 39, 96-104.

Parrot, L., Sotamenou, J., \& Dia, B. K. (2009). Municipal solid waste management in Africa: Strategies and livelihoods in Yaoundé, Cameroon. Waste Management, 29(2), 986-995. https://doi.org/10.1016/j.wasman.2008.05.005

Peter, L. L., \& Yang, Y. (2019). Urban Planning Historical Review of Master Plans and The Way Towards a Sustainable City: Dar es Salaam, Tanzania. Frontiers of Architectural Research. https://doi.org/10.1016/j.foar.2019.01.008

Ramaswami, A., Baidwan, N. K., \& Nagpure, A. S. (2016). Exploring social and infrastructural factors affecting open burning of municipal solid waste (MSW) in Indian cities: A comparative case study of three neighborhoods of Delhi. Waste Management \& Research, 34(11), 1164-1172.

Remigios, M. V. (2010). An Overview of the Management Practices at Solid Waste Disposal Sites in African Cities and Towns. Journal of Sustainable Development in Africa, 12, 233-9 
Schubeler, P., Coolidge, G. J., Porter, C. R., \& Zhang, Z. J. (1998). Urban environmental services in developing countries. Michigan: Department of Economics, University of Michigan.

Simelane, T., \& Mohee, R. (2015). Future directions of municipal solid waste management in Africa. Pretoria: Africa Institute of South Africa. Retrieved from http://search.ebscohost.com.ezproxy.aee.talonline.ca/login.aspx?direct=true\&AuthType=ip,cookie,url,uid\& $\mathrm{db}=$ nlebk\&AN=992556\&site $=$ ehost-live\&scope $=$ site

Silva, C. N. (2013). Urban planning and public health in Africa. Historical, theoretical and practical dimensions of a continent's water and sanitation problematic. Planning Perspectives, 28(3), 508-510. https://doi.org/10.1080/02665433.2013.800710

Sotamenou, J., Ganry, F., Montange, D., Parrot, L., \& Simon, S. (2010). Transfer stations for sustainable municipal solid waste management in Africa: Evidence from Cameroon. Solid Waste Management \& Environmental Remediation. New York: Nova Science Publishers, 217-242.

Tchobanoglous, G., Theisen, H., \& Vigil, S. A. (1993). Integrated solid waste management. engineering principles and management issues. Singapore: McGraw-Hill.

Thompson, I. A. (2008). Domestic waste management strategies in Accra, Ghana and other urban cities in tropical developing nations. Ohio: Case Western Reserve University. Retrieved May 24, 2012, from http://www.cwru.edu/med/epidbio/mphp439/Waste_Mgmt_Accra.pdf

Wang, Q., Kwan, M. P., Zhou, K., Fan, J., Wang, Y., \& Zhan, D. (2019). The impacts of urbanization on fine particulate matter (PM2. 5) concentrations: Empirical evidence from 135 countries worldwide. Environmental Pollution, 247, 989-998.

Watson, J., D'Mello-Guyett, L., Flynn, E., Falconer, J., Esteves-Mills, J., Prual, A., ... Cumming, O. (2019). Interventions to improve water supply and quality, sanitation and handwashing facilities in healthcare facilities, and their effect on healthcare-associated infections in low-income and middle-income countries: a systematic review and supplementary scoping review. BMJ global health, 4(4), e001632.

Zhao, Y., Lu, W., \& Wang, H. (2015). Volatile trace compounds released from municipal solid waste at the transfer stage: evaluation of environmental impacts and odour pollution. Journal of Hazardous Materials, 300, 695-701. https://doi.org/10.1016/j.jhazmat.2015.07.081

\section{Copyrights}

Copyright for this article is retained by the author(s), with first publication rights granted to the journal.

This is an open-access article distributed under the terms and conditions of the Creative Commons Attribution license (http://creativecommons.org/licenses/by/4.0/). 